Artigo original

Hegemonia - Revista Eletrônica de Relações Internacionais do Centro Universitário Unieuro

ISSN: $1809-1261$

UNIEURO, Brasília, número 11, 2013, pp. 69-98

Recebido em: 26/1/2013

Revisado em: $3 / 2 / 2012$

Aprovado em: 25/2/2013

\title{
OS DILEMAS CLÁSSICOS SOBRE A DEMOCRACIA, PARTIDOS POLÍTICOS E SEUS RELEXOS PARA A REFORMA POLÍTICA BRASILEIRA
}

TEIXEIRA, Rodolfo Marcilio ${ }^{1}$

Resumo: Este trabalho busca expor os vários conceitos de democracia e partido político, assinalando seus principais paradigmas e procurando demonstrar a complexidade da discussão teórica. Com base em pesquisas sobre o apoio à democracia e as instituições políticas, ele ressalta como a multiplicidade de definições e modelos impacta negativamente na consolidação destas instituições, sobretudo na América Latina. Finalmente, assevera que o processo de consolidação da democracia exige mudanças institucionais que não sejam limitadas apenas a questões procedimentais.

Palavras-chave: democracia, participação, partidos, reforma política, representação.

Abstract: This paper seeks to explain the various concepts of democracy and political party, noting its major paradigms and seeking to demonstrate the complexity of the theoretical discussion. Based on several studies that address the support for democracy and political institutions, it highlights how the multiplicity of definitions and models impacts negatively on consolidating these institutions, especially in Latin America. Finally, it asseverates that the process of consolidating democracy requires institutional changes that are not only limited to procedural issues.

Keywords: democracy, participation, parties, political reform, representation.

Doutor em Sociologia e Mestre em Ciência Política pela Universidade de Brasília (UnB). Professor do Mestrado em Ciência Política UNIEURO. Educador Social da Secretaria de Desenvolvimento Social e Transferência de Renda SEDEST/GDF. 
Artigo original

Hegemonia - Revista Eletrônica de Relações Internacionais do Centro Universitário Unieuro

ISSN: $1809-1261$

UNIEURO, Brasília, número 11, 2013, pp. 69-98

Introdução

Qualquer processo democrático de reforma do sistema político que almeje ser bem sucedido, seja pelo fortalecimento da representatividade, seja pelo reforço à governabilidade, necessita de um arcabouço filosófico estruturado. Contudo, a tarefa de estabelecer esta estrutura apresenta problemas complexos cujos resultados práticos têm deixado bastante a desejar, como mostram as pesquisas de opinião pelo mundo. A satisfação média com a democracia em 25 países da União Europeia no ano de 2006 foi de 54\%. França e Portugal apresentaram, respectivamente, $40 \%$ e 30\%. Na América Latina a média de satisfação entre os anos de 1998 e 2006 variou entre $25 \%$ e $37 \%$ (Mangahas; 2007).

No que diz respeito aos partidos políticos, os níveis de satisfação são ainda mais baixos. Os dados apresentados por Dalton \& Weldon (2005) mostram que a opinião geral sobre estas instituições é, na maioria das vezes, negativa. O crescente quadro de desconfiança contribui para reduzir a participação em eleições; para fragmentar os sistemas partidários; e para fortalecer os partidos de protesto, conjunto de fatores que também ajudam a deteriorar a opinião em relação aos governos, a exemplo do que pode ser verificado recentemente nas eleições gerais da Grécia (2012) e da Itália (2013).

Estes problemas ocorrem porque a estrutura interna de qualquer sistema eleitoral, assim como os objetivos aos quais ele se presta, é definida pelo tipo de democracia almejada pelos seus idealizadores. Por conseguinte, o sistema eleitoral também contribuirá para definir, em maior ou menor grau, que tipo de sistema partidário será estabelecido: a quantidade de partidos políticos; a estrutura interna; e os instrumentos que estes têm ao seu dispor para melhor representar os valores e ideais da sociedade ao qual pertencem e representam. Logo, um sistema eleitoral pode tanto ajudar a gerar partidos estruturalmente fortes, socialmente 
Artigo original

Hegemonia - Revista Eletrônica de Relações Internacionais do Centro Universitário Unieuro

ISSN: 1809-1261

UNIEURO, Brasília, número 11, 2013, pp. 69-98

enraizados, internamente coesos e disciplinados, quanto pode também produzir resultados opostos. Este conjunto de escolhas é fundamental para determinar o tipo de relação a ser estabelecida entre a sociedade e o Estado, tendo os partidos como intermediadores. Sendo assim, a busca por sentidos e objetivos claros para os termos democracia e partidos políticos torna-se imprescindível para a discussão sobre o sistema eleitoral.

Vale lembrar que ambos são condicionados pelas experiências históricas e culturais de cada povo, transmutam de acordo com as novas formas de interação social proporcionadas por novas tecnologias e são influenciados pelas mudanças estruturais e conjunturais na economia, na política e na cultura. Esta fluidez de sentido representa tanto a possibilidade de projetos democráticos criativos e inclusivos quanto o estabelecimento de experiências pseudodemocráticas. Em um jogo onde pequenas mudanças conceituais podem trazer resultados práticos tão diversos, e onde a distância entre beneficiados e prejudicados pode ser colossal, não se deve esperar que determinados instrumentos de escolha da representação sejam unânimes. De todo modo a tarefa de responder quais são os limites conceituais para a formulação dos sistemas políticos é inescapável.

Este artigo procura apontar alguns dos principais problemas teóricos que envolvem a discussão sobre a democracia e os partidos políticos. É importante ressaltar que estes temas não podem ser associados a um autor ou escola específica de pensamento. Não obstante, apesar de toda problemática de conceitualização, eles se tornaram valores universais para as democracias ocidentais. Não é objetivo deste trabalho proporcionar uma discussão aprofundada que apresente as diversas proposições tanto dos clássicos quanto dos contemporâneos. Portanto, para ambos os casos, limitou-se a um conjunto de autores específico.

Perspectivas de democracia e seu impacto na participação 
Artigo original

Hegemonia - Revista Eletrônica de Relações Internacionais do Centro Universitário Unieuro

ISSN: $1809-1261$

UNIEURO, Brasília, número 11, 2013, pp. 69-98

O desenvolvimento da filosofia das ciências demonstrou que uma palavra pode incorporar significados bastante diferentes em várias esferas do conhecimento. Dentre estes, vale ressaltar 0 conceito de democracia, tema bastante controverso, fluido e capaz de gerar imensa discordância. A discussão sobre a democracia proporciona múltiplos pontos de vista. Entre eles, a perspectiva representativa de Schumpeter (1961) e Dahl (1997) - onde o processo decisório baseia-se num conjunto de procedimentos para agregar e apresentar os diversos interesses individuais em um mercado político. Em segundo lugar, a perspectiva participativa influenciada pela experiência de Atenas e defendida por Pateman (1992) - onde a participação política não é apenas um instrumento do processo decisório, mas um objetivo que auxilia na formação do ser humano.

A perspectiva representativa, desenvolvida primeiramente pelos utilitaristas Jeremy Bentham e John Mill, parte do princípio da maximização das vontades do ser humano para defender a liberdade do cidadão, garantindo o controle dos organismos de Estado por meio de um governo representativo. As novas características dos Estados, cada vez mais distantes da experiência ateniense, exigem um modelo renovado de democracia, cuja base fundamental não está mais na participação direta, mas no estabelecimento de eleições e no uso dos partidos políticos como principais intermediadores dos desejos e ansiedades de seus representados.

Neste sentido, Schumpeter (1961) tornou-se um dos principais expoentes da democracia representativa. Sua percepção da doutrina clássica como distinta da realidade tornou-se fundamental para uma nova concepção de democracia. Ele enuncia que o problema mais importante do entendimento clássico de democracia está no pronto aceite das seguintes proposições: primeiramente, que "as pessoas" possuem uma opinião racional e definitiva a respeito de todo e qualquer questionamento individual; em segundo lugar, que os representantes escolhidos garantirão que as opiniões dos eleitores serão levadas a cabo. Em outras palavras, o argumento racional seria capaz de levar todo e qualquer indivíduo - assim como seus 
Artigo original

Hegemonia - Revista Eletrônica de Relações Internacionais do Centro Universitário Unieuro

ISSN: 1809-1261

UNIEURO, Brasília, número 11, 2013, pp. 69-98

representantes eleitos - a enxergarem conjuntamente determinadas respostas para os obstáculos ao bem-estar e à felicidade.

O autor procura se esquivar de tais considerações. Para isso, define o método democrático da seguinte forma: um arranjo institucional que chega a decisões políticas nas quais indivíduos específicos adquirem o poder de deliberar, com base no embate competitivo por votos. Segundo ele, este modelo melhora substancialmente a teoria do processo democrático, uma vez que não cai nas armadilhas conceituais ("vontade comum", "bem comum" e "natureza humana") empregadas pelos utilitaristas. Mais ainda, ele aponta que este modelo prescinde de outras influências prejudiciais (de cunho religioso, por exemplo) de que os utilitaristas também não conseguiram se desvencilhar ${ }^{2}$.

Schumpeter (op. cit.) sugeriu uma nova abordagem onde a eleição de representantes é mais importante que a participação direta do cidadão nas decisões políticas. Sendo assim, são descartados os conceitos de "vontade comum" e "natureza humana". De acordo com esta perspectiva, o que conceitua a democracia não é a primazia da vontade popular como regente da ação dos governantes. Ao contrário, a soberania popular é consolidada pela escolha dos representantes no processo eleitoral. Nestes termos, a contribuição deste autor pode ser considerada o marco inicial para diversas abordagens posteriores. Apesar de ter colaborado enormemente para a discussão, o pensamento de Schumpeter está longe de ser uma unanimidade. Suas propostas encontram em outros autores convergências e divergências bastante significativas. Cabe salientar, primeiramente, as convergências.

Para Sartori (1994), apesar de ser amplamente aceito em várias sociedades, o termo democracia encontra diversos tipos de resistência quanto à sua formulação. Em sua concepção, todas as convenções são arbitrárias e individualizadas e têm oscilado entre a

A esse respeito, Schumpeter apresenta o conceito de "natureza humana na política", ou seja, a dificuldade dos "cidadãos" comuns para lidar com problemas que vão além do seu cotidiano pessoal e profissional (Costa, 2000, p. 7). 
Artigo original

Hegemonia - Revista Eletrônica de Relações Internacionais do Centro Universitário Unieuro

ISSN: 1809-1261

UNIEURO, Brasília, número 11, 2013, pp. 69-98

análise excessivamente descritiva e a defesa exagerada de determinados valores. Este autor aponta que o termo democracia não é mais do que uma definição que se limita a reproduzir em um idioma conhecido o significado grego do termo. Logo, defende que este ideal não define a realidade democrática, e vice-versa. Em outras palavras, uma democracia real não significa uma democracia ideal baseada na busca pela efetivação do "poder do povo". Assim como Schumpeter, Sartori (op. cit.) advoga que, embora o consenso sobre um grupo de valores fundamentais facilite, o mesmo não é condição necessária à democracia. Em contraposição, o consenso procedimental, ou seja, a concordância em relação às formas de resolução de conflitos e normas complementares é a condição necessária. Em outras palavras, o consenso procedimental é o verdadeiro pré-requisito da democracia.

Seguindo uma linha semelhante, Dahl (2001, p. 48) salienta que a palavra democracia "é usada de maneiras pasmosamente diferentes". Mais ainda, observa que: "na linguagem comum usamos o termo tanto para nos referirmos a um objetivo ou ideal como a uma realidade que é apenas uma consecução parcial deste objetivo" (idem, p.97). Diante desta confusão, assinala um conjunto de critérios $^{3} \mathrm{e}$ instituições ${ }^{4}$ tidos como característicos (e necessários) deste regime, ressaltando, porém, que "nenhum Estado jamais possuiu um governo que estivesse plenamente de acordo com todos os critérios de um processo democrático" (id.ibid, p. 53). Novamente, o conceito tem importância menor quando comparado à necessidade de se estabelecer um procedimento. Não obstante, Dahl procura avançar na discussão, apresentando as democracias modernas (atuais) como poliarquias, ou seja, "governos de muitos" - dotados de um conjunto específico de instituições que se estabelecem e repartem o poder.

Critérios: Participação efetiva; igualdade de voto; entendimento esclarecido; controle definitivo do planejamento; inclusão dos adultos.

Instituições: Funcionários eleitos, eleições livres, justas e frequentes; liberdade de expressão; fontes de informação diversificadas; autonomia para as associações e cidadania inclusiva. 
Artigo original

Hegemonia - Revista Eletrônica de Relações Internacionais do Centro Universitário Unieuro

ISSN: 1809-1261

UNIEURO, Brasília, número 11, 2013, pp. 69-98

Para Dahl \& Lindblom (1971) a democracia é um objetivo a ser alcançado num contexto de igualdade política. Neste caso, as vontades de indivíduos diferentes têm o mesmo peso, mas prevalece o desejo da maioria. Também assinala que este cenário exige alguns pré-requisitos. É preciso que exista uma concordância geral em relação ao método de competição política num contexto de pluralismo social onde a desigualdade econômica é combatida e restringida. Além disso, é necessário que se estabeleça um cenário que possibilite a ascensão de novas lideranças. Dahl (2001, p. 48) também segue apontando que a democracia é a forma de governo que avaliza uma série de direitos e garantias fundamentais que os sistemas nãodemocráticos não proporcionam (e nem podem proporcionar). Para isso, ela necessita de uma cultura política que atue como sustentáculo de apoio aos seus ideais e práticas.

Pateman (1992) é considerada um dos expoentes da corrente que defende a democracia participativa. Segundo essa perspectiva, a democracia é sustentada pelo modelo de cidadão participativo encontrado em Atenas. Os seguidores desta linha não propõem um rompimento total com a perspectiva representativa. Ao contrário, eles sugerem o estabelecimento de eleições para os cargos políticos concomitantemente à criação de mecanismos de participação direta que sejam capazes decidir sobre determinadas questões e influir no comportamento dos representantes eleitos quando necessário. Neste contexto, A autora citada acima critica o conceito estabelecido por Schumpeter. Para ela, este pensador destacou a competição pela liderança política como fator fundamental. Logo, a participação ocorreria pela eleição, ocupando pouco espaço na teoria Schumpeteriana, uma vez que o funcionamento do sistema político estaria focado na ação dos líderes. Contrariamente, a autora vislumbra que as sementes da democracia participativa, vistas nos clássicos da antiguidade, foram erroneamente suplantadas pela perspectiva democrática fundamentada na concorrência entre lideranças.

Przeworski (1998) analisa o contraste entre estas duas perspectivas (representativa e participativa). Ele aponta que, de fato, 
Artigo original

Hegemonia - Revista Eletrônica de Relações Internacionais do Centro Universitário Unieuro

ISSN: 1809-1261

UNIEURO, Brasília, número 11, 2013, pp. 69-98

quando se discute o conceito, existe uma contraposição entre a ideia de uma democracia meramente política - caracterizada pelo formalismo - e a de uma democracia substantiva, definida pelo seu cunho social. Este pensador mostrou-se bastante resistente à tendência difundida de valorizar uma concepção "maximalista". Ao contrário, enfatiza à importância da clareza analítica para o tema. Neste sentido, aponta que é necessária a utilização de uma acepção "minimalista". Isto porque, em última análise, os direitos civis já são garantidos pelo "Estado de direito". Neste sentido a democracia é apresentada como um sistema regulado de escolha de representantes, onde os resultados podem ser previsíveis, mas não conhecidos previamente. Sendo assim, o principal âmbito de disputa entre os interesses políticos consiste nas eleições.

Contrariamente, Reis (2000) aponta que o conjunto da visão "minimalista" proposta acima possui inconsistências. Segundo ele, o mesmo Przeworski deixa escapar que certas condições de desigualdade social - onde os recursos diversos de poder estão disseminados de modo desigual - geram entraves à consolidação de uma democracia que garanta a plenitude dos direitos políticos e civis. Reis (op. cit) salienta ainda que (ao contrário do que propõe a visão minimalista) a articulação de acordos em torno de políticas públicas, de conteúdo econômico e social, entre diferentes grupos da sociedade civil e o Estado é imprescindível para a construção e manutenção da estabilidade institucional que caracteriza o "compromisso democrático". Para cumpri-lo o autor advoga em favor da ideia da construção de uma democracia em que os arranjos institucionais são bem articulados. Neste modelo, o Estado precisa agir na busca do interesse público com um nível adequado de autonomia em relação aos interesses sociais particulares. Em contrapartida, o todo social necessita da disponibilidade de agentes autônomos - individuais e coletivos - capazes de atuar com liberdade e, na medida do admissível, igualdade ${ }^{5}$.

A incapacidade de atingir este objetivo indica uma aproximação ao que Costa (2000) apontou como sendo a não institucionalização da democrática. Reis (2000) também trata do termo "ingovernabilidade pretoriana" que possui semelhanças. 
Artigo original

Hegemonia - Revista Eletrônica de Relações Internacionais do Centro Universitário Unieuro

ISSN: 1809-1261

UNIEURO, Brasília, número 11, 2013, pp. 69-98

De acordo com O'Donnel (citado por Paiva et. al., 2004, p. 369), "a democracia está consolidada quando existe um 'consenso processual' mínimo com relação às instituições poliárquicas, quais sejam, o voto secreto, o sufrágio universal, eleições regulares, competição partidária, acesso e reconhecimento das associações e accountability ${ }^{6}$ do Executivo". Nesta conjuntura, ao contrário do que propôs Dahl, "a democratização das relações sociais, para além da esfera política, não é condição, mas consequência eventual do funcionamento habitual e do fortalecimento das instituições poliárquicas".

O'Donnell $(1991,31)$ também assinala que "a democracia é a constituição, em eleições limpas, de uma maioria que autoriza alguém a se tornar, por um determinado número de anos, a encarnação e o intérprete dos altos interesses da nação". A partir disso, os fatores mais determinantes na construção de uma democracia - aqueles que parecem ter mais peso - são, primeiramente, traços históricos de longo prazo e, em segundo lugar, a dimensão da crise $^{7}$ socioeconômica que os novos governos herdam. Sendo assim, sugere que "as teorias e tipologias existentes se referem à democracia representativa tal como é praticada, com todas as suas variações e subtipos, pelos países capitalistas desenvolvidos". O fato de algumas nações da América Latina preencherem os critérios estabelecidos por Dahl não as confirma como sendo ou caminhando no sentido de se tornarem verdadeiras democracias representativas. Este autor salienta também que a grave crise social e econômica que a maioria dos países Latino-americanos herdou de regimes autoritários "multiplica poderosamente as consequências de certas

Accountability: Em Mainwaring (2001; p. 34) este termo é traduzido como "mecanismos institucionais que asseguram a responsabilização dos diferentes agentes políticos pelo exercício das funções de representação política ou do governo concernentes ao mandato que detêm".

Para O 'Donnell $(1991,31)$ "Inflação extrema, estagnação econômica, uma profunda crise financeira do Estado, uma enorme dívida pública externa e interna, e uma acentuada deterioração das políticas e dos serviços sociais públicos, são aspectos dessa crise." 
Artigo original

Hegemonia - Revista Eletrônica de Relações Internacionais do Centro Universitário Unieuro

ISSN: 1809-1261

UNIEURO, Brasília, número 11, 2013, pp. 69-98

concepções e práticas que conduzem na direção da democracia delegativa, e não representativa". Segundo O'Donnell (op. cit.), no modelo delegativo, os eleitores destinam ao governante plenos poderes. Em contrapartida, nas democracias representativas os governantes devem prestar contas de suas ações. Em outras palavras, a distinção entre esses dois tipos de democracia encontrase na accountability: fraca (ou inexistente), nas democracias delegativas, e consolidada nas democracias representativas estáveis. Muito embora a democracia delegativa não seja consolidada ou institucionalizada, isso não significa que não possa ser duradoura.

A seguir estão resumidos outros aspectos relativos à democracia delegativa, na perspectiva de O'Donnell (op. cit, 32-33). Ela tem uma conotação profundamente individualista e possui um caráter fortemente majoritário para sustentar o que este autor chamou de "mito da delegação legítima". Suas eleições são, de modo geral, processos exageradamente emocionais onde um amplo grupo de candidatos compete pela administração. Uma vez eleitos, não sofrem "quaisquer outras restrições a não ser por aquelas impostas pelas relações de poder nuas, isto é, não institucionalizadas". Além da participação eleitoral, não é esperado dos eleitores nada além da volta à condição de espectadores passivos. Mais ainda, há uma série de antagonismos entre a tecnocracia protegida ${ }^{8}$, o Congresso, partidos, trabalhadores, capitalistas e a sociedade civil como um todo. Em muitos casos, os tribunais abusam de legalismos e formalismos no tratamento de "medidas flagrantemente inconstitucionais". A democracia delegativa também garante ao presidente muito poder e pouca obrigatoriedade de prestar contas. "Ela permite a elaboração rápida de políticas que estão sujeitas a uma alta probabilidade de erros grosseiros, de implementação incerta, e de uma altíssima concentração de responsabilidade pelos resultados no presidente". Nestes termos, o frequente isolamento

Sobretudo quanto aos encarregados da política econômica. O Donnell aponta que as exigências de diversos grupos em relação à conduta da economia são, constantemente, desconsideradas. 
Artigo original

Hegemonia - Revista Eletrônica de Relações Internacionais do Centro Universitário Unieuro

ISSN: 1809-1261

UNIEURO, Brasília, número 11, 2013, pp. 69-98

político do presidente potencializa sua inclinação "a evitar, ignorar e/ou corromper essas e outras instituições".

Finalmente, O`Donnell aponta que - tomando como exemplo as democracias consolidadas - a edificação de uma lógica representativa pela construção de instituições eficazes e de práticas políticas inerentes "não pode ser implantada por decreto". Ao contrário, "o surgimento, fortalecimento e legitimação dessas práticas e instituições demandam tempo, durante o qual está envolvido um complexo processo de aprendizado positivo".

Lijphart $(2003)^{9}$, por sua vez, parte de outros pontos para estabelecer sua visão de democracia. Ao citar Arthur Lewis, este autor aponta que o pressuposto fundamental do modelo democrático é que "todos aqueles afetados por uma decisão devem ter a oportunidade de participar do processo que a originou, quer diretamente, quer através de representantes escolhidos". ${ }^{10} \mathrm{O}$ segundo ponto consiste em que a vontade da maioria deve preponderar. Isso não significa que, enquanto os vitoriosos monopolizam as deliberações governamentais, aqueles que foram derrotados eleitoralmente devem ficar satisfeitos com o afastamento do poder (e do governo), limitando-se à crítica distanciada. Ao contrário, "excluir os grupos perdedores da participação nos processos decisórios é uma nítida violação do principal pressuposto de democracia". Esta conclusão é resultado de trabalhos anteriores (Lijphart, 1994 e 1999) onde este autor faz comparações entre sistemas consensuais e majoritários objetivando identificar o melhor modelo. De modo geral, o primeiro pode ser identificado pela divisão de poder e pelo compromisso com coalizões amplas, enquanto o segundo é identificado pelo fato de que "o vencedor leva tudo". Ele assinala que, embora ambos atinjam níveis similares de eficiência, o consensual obtêm melhores níveis de participação e satisfação. Além disso,

Capítulo 3: O modelo Consensual de Democracia.

Este pressuposto torna-se bem mais complexo na atualidade, uma vez que, no mundo globalizado, certas decisões adotadas pelas potências econômicas podem ter impacto em um número substancial de países. 
Artigo original

Hegemonia - Revista Eletrônica de Relações Internacionais do Centro Universitário Unieuro

ISSN: $1809-1261$

UNIEURO, Brasília, número 11, 2013, pp. 69-98

contribui de melhor maneira na diminuição dos graus de desigualdade, desde que constituído por um conjunto de instituições como o bicameralismo, o federalismo, a rigidez constitucional e revisão pelo Poder Judiciário, entre outras.

Definição de Partido Político e Dilemas Clássicos

A noção de partido político, como compreendida nos dias de hoje, é bastante recente. Embora organizações semelhantes ${ }^{11}$ sejam consideradas embriões dos partidos políticos atuais (Sartori, 1976), não possuem a mesma estrutura. Neste período, programas de governo devidamente estruturados e atividades políticas fora do parlamento não eram comuns. Estes grupos não se ligavam à vontade popular, agindo em prol de interesses específicos no âmbito institucional. O conceito de partido político atual surgiu apenas ao longo do Século XIX a partir da expansão do sufrágio. Silva (2007) assinala que o reconhecimento jurídico e institucional aconteceu apenas no Século XX, sobretudo após a Segunda Guerra.

Vários estudiosos abordaram a questão da definição de partido político apresentando pontos convergentes e divergentes. Costa (2000) aponta que, para Weber, estas organizações são estabelecidas de maneira voluntária e visam a um fim deliberado, seja ele objetivo como a realização de um plano com intuitos materiais ou ideais, seja pessoal, destinado a obter benefícios e poder. Possivelmente, um partido pode se voltar para todos esses objetivos conjuntamente.

Na concepção de Michels (1982), a experiência dos grandes partidos políticos de esquerda da Europa Ocidental do início do século

Guelfos e Guibelinos, na Idade Média, ou os jacobinos e Gerondinos na França do Século XVIII. 
Artigo original

Hegemonia - Revista Eletrônica de Relações Internacionais do Centro Universitário Unieuro

ISSN: $1809-1261$

UNIEURO, Brasília, número 11, 2013, pp. 69-98

XX revela que as agremiações partidárias, instituições inicialmente arquitetadas para propiciar o desenvolvimento da democracia política, tornam-se, inevitavelmente, oligárquicas. Para ele, este fenômeno é uma tendência inexorável porque o imperativo da liderança transforma as organizações, suscitando a necessidade de uma classe profissional experiente e capaz de centralizar a administração. Por conseguinte, a oligarquização dos partidos enfraquece as outras instituições políticas e termina por prevalecer frente aos princípios democráticos, colocando as sociedades política e civil em risco de desagregação.

De acordo com Field (1959), os partidos políticos são organizações voluntárias de pessoas com a finalidade de conquistar o poder por meios constitucionais. Neste sentido, um partido não está naturalmente comprometido para sempre com qualquer linha política em especial, podendo alterá-la no todo ou em parte e ainda permanecer a mesma legenda. De outra forma, assinala que um partido é muito semelhante a um cometa, tendo um núcleo sólido na cabeça e uma longa cauda gasosa a segui-lo.

Miliband (1985) expõe que os partidos políticos analisados em Marx no século XIX não têm semelhança com as máquinas partidárias atuais. Mesmo assim é possível fazer considerações pertinentes utilizando a análise marxista. Esta linha entende estas agremiações como parte de um processo histórico mais amplo de transformação social denominado movimento político. Em sua revisão, Miliband afirma que na totalidade dos países capitalistas existem partidos que são favorecidos como veículos ou instrumentos das classes dominantes, constituídas pelos detentores de negócios e propriedades.

Bonavides (1974, p. 429) afirma que, apesar da multiplicidade de significados que são encontrados, podemos deduzir uma tendência comum para a composição e ordenamento dos partidos. Esta composição se estabelece da seguinte forma: "um grupo social; um princípio de organização; um acervo de ideias e princípios que inspiram a ação do partido; um interesse básico em vista: a tomada do poder; e finalmente, como sentimento de conservação deste poder 
Artigo original

Hegemonia - Revista Eletrônica de Relações Internacionais do Centro Universitário Unieuro

ISSN: 1809-1261

UNIEURO, Brasília, número 11, 2013, pp. 69-98

ou de domínio do aparelho governativo quando este lhes chega às mãos".

Tomando como base as considerações citadas acima, é possível estabelecer uma série de pontos importantes. A única convergência em todos os autores a respeito das legendas é aquela relativa ao comprometimento com a aquisição, divisão e manutenção do poder. No somatório das percepções, não foi dada muita ênfase ao compromisso de longo prazo com princípios ou ideologias a serem defendidas. Nem mesmo compromissos efetivos quanto a implementação de políticas democráticas dentro da agremiação partidária. Com base nas definições, é possível concluir, portanto, que os partidos políticos não precisam, necessariamente, ser instituições democráticas, apesar de serem imprescindíveis à democracia representativa. Este aspecto gera um peculiar paradoxo onde a fragilidade dos sistemas partidários nas sociedades modernas fica sem resposta. Além de oferecerem um excessivo grau de liberdade para as instituições partidárias e indivíduos que as compõem, as definições acima não tratam de questões relativas aos deveres e responsabilidades dos partidos, assim como não abordam obrigações que pudessem ser apresentadas como formas mais simples de accountability. De fato, diversos autores atentaram para o assunto e assinalaram a necessidade de revisão do conceito, direitos, deveres e funções dos partidos políticos e outras instituições como forma de ampliar e fortalecer a democracia (Comparato, 2003; Trindade, 2003; Benevides, 2003; Abrucio, 2003, entre outros).

Em face deste problema, é preciso delinear uma nova visão sobre os partidos políticos, mais adequada a nova realidade exposta anteriormente. Nesta linha, Hofnung (2008, p. 728) expõe que durante décadas as legendas foram vistas como "associações voluntárias" que tinham como finalidades "a promoção de uma agenda ideológica, o engajamento na mobilização social e esforços educacionais". Para este autor, "essa abordagem não é mais dominante". Hoje em dia, faz-se necessário que os partidos sejam compreendidos, sobretudo, pelas suas relações com o Estado. Em outras palavras, eles são "instituições semipúblicas" que têm um 
Artigo original

Hegemonia - Revista Eletrônica de Relações Internacionais do Centro Universitário Unieuro

ISSN: 1809-1261

UNIEURO, Brasília, número 11, 2013, pp. 69-98

importante papel na democracia. Desta forma, precisam ser transparentes e saudáveis financeiramente para que possam responder às demandas da sociedade.

Com base nesta última visão - e outras similares - as legendas devem, primeiramente, ser concebidas como instituições de direito semipúblico cujos laços com o Estado são mais fortes do que os laços com a sociedade devido à lógica da competição eleitoral, ao uso do financiamento público e à política de partidarização dos cargos. Em segundo lugar, é preciso compreender que, na grande maioria dos casos, as legendas também não mais defendem ideologias. Ao contrário, representam modelos de gestão diferenciados que estão sujeitos à avaliação e escrutínio do eleitor. Mesmo nos raros casos em que ideologias e valores específicos venham a ser bandeiras, é preciso aceitar que eles são relativamente fluidos e passíveis de serem modificados ao longo dos anos, sobretudo na eventualidade de uma transição do governo para a de oposição e vice-versa.

Em terceiro lugar, é preciso inserir valores democráticos na concepção de partido político. Não apenas por serem pilares da democracia, mas pelo fato de que eles vêm aumentando sistematicamente a utilização de receitas públicas como principal meio de sustentação. Isso implica combate a oligarquização através de regras que delimitem a competição interna (pré-eleitoral) para que a mesma seja, cada vez mais, inclusiva e transparente. Esse conjunto de fatores tem claro reflexo sobre a maneira como se deve discutir as alianças eleitorais e a fidelidade partidária, assim como a necessidade de uma revisão sobre as formas de fiscalização e controle das receitas e despesas das legendas.

Uma vez explicitado o problema da conceitualização de partido político, é possível tratar outros temas que serão de grande utilidade na discussão sobre a necessidade de uma reforma política no Brasil.

Paradigmas envolvendo Partidos e Sistemas Eleitorais 
Artigo original

Hegemonia - Revista Eletrônica de Relações Internacionais do Centro Universitário Unieuro

ISSN: 1809-1261

UNIEURO, Brasília, número 11, 2013, pp. 69-98

Sartori (1996) aponta que a lógica interna dos partidos (e do sistema partidário como um todo) afeta o sistema eleitoral. Com base nisso é possível dizer que sistemas partidários oligarquizados trazem consequências negativas para a democracia, fato que enfraquece o sistema político gerando um ciclo vicioso. Michels (1982) revela que a razão para o processo de oligarquização dos partidos tem dois núcleos. O primeiro remete à necessidade que os Estados têm de organizações políticas estáveis. O segundo núcleo assinala que as massas não estão preparadas para a prática efetiva da democracia e, consequentemente, estão predispostas a ceder o controle partidário em favor de uma oligarquia. Noutras palavras, todo aparelhamento minimamente organizado e eficiente, por razões de ordem tática e técnica, precisa de chefes. Esta necessidade cria uma forma de organização que é, ao mesmo tempo, a fonte da dominação. Em suma, "quem diz organização, diz oligarquia" (ibid., p. 238). Este antagonismo permanente entre a oligarquia inerte e a participação democrática dentro dos partidos é um dos pontos centrais do debate político sobre a necessidade e efetividades dos sistemas partidários.

Além do paradigma da oligarquização, mencionado acima, tem-se a questão da dimensão das relações interpartidárias. Duverger (1962, p. 362) aponta que as relações entre alianças eleitorais e alianças governamentais são muito complexas, sendo que a segunda não requer necessariamente a primeira, e vice-versa. Para este autor, é mais fácil a união em busca da conquista de postos no parlamento através de acordos momentâneos, do que uma aliança estável pela divisão do poder. Esta última demanda a aceitação de um programa comum e mais afinidade entre as partes. Sendo assim, existe outro caráter contraditório relativo ao processo eletivo, sobretudo nos sistemas proporcionais. Uma vez consolidado este processo, são firmadas alianças governistas diversas das encontradas no pleito porque raramente um partido atinge a maioria absoluta no parlamento. Noutras palavras, "tornando os partidos totalmente independentes uns dos outros no primeiro momento e, obrigando-os a colaborar no segundo. Normalmente, isso torna mais difícil a 
Artigo original

Hegemonia - Revista Eletrônica de Relações Internacionais do Centro Universitário Unieuro

ISSN: $1809-1261$

UNIEURO, Brasília, número 11, 2013, pp. 69-98

formação de coligações parlamentares estáveis e duradouras. Mais ainda, torna mais instável o destino das maiorias governamentais".

Paradigma sobre as Funções dos Partidos no Âmbito Democrático

Existem visões divergentes sobre a função e o papel apropriado dos partidos políticos. Zovatto (2005, p. 02) cita Sartori ao salientar a importância deles para os sistemas democráticos, "sem os quais ela não seria viável". De acordo com Norris (2005, p. 03), os partidos políticos podem servir a múltiplas funções. Eles são necessários para construir e agregar suporte entre coalizões amplas de organizações e grupos de interesse; para transformar múltiplas demandas conflitantes em políticas programáticas coerentes; para selecionar e treinar líderes políticos; para prover os eleitores com escolhas entre equipes de governo e políticas e; se eleitos, para organizar o processo de governo e ser responsabilizado coletivamente por suas ações em eleições posteriores. Consequentemente, a democracia representativa não é possível sem uma competição partidária, uma vez que os partidos políticos funcionam de acordo e constituem um dos pilares desta sociedade. A longa lista de funções potenciais pode ser sumarizada em cinco aspectos principais:

a) a integração e mobilização de cidadãos;

b) a articulação e agregação de interesses;

c) a formulação de políticas públicas;

d) o recrutamento de líderes políticos e;

e) a organização do poder legislativo e do governo.

Alguns dos autores contemporâneos - advogados das democracias participativas, diretas ou deliberativas - vislumbram os partidos com suspeição, sob a premissa de que os cidadãos deveriam discutir os temas e estabelecer prioridades dentro de cada comunidade, sem a influência de interesses partidários. Esta 
Artigo original

Hegemonia - Revista Eletrônica de Relações Internacionais do Centro Universitário Unieuro

ISSN: 1809-1261

UNIEURO, Brasília, número 11, 2013, pp. 69-98

perspectiva, embora modificada, tem suas raízes em Madison ${ }^{12}$ e Rousseau (1986), autores que viam os partidos como interesses estranhos aos representados, propensos a fragilizar, perverter ou usurpar a vontade da maioria. Nesta perspectiva, os partidos seriam organizações artificiais, descompromissadas e constituídas por candidatos que constroem imagens pessoais vagas (Manin, 1995). Mais ainda, estas "facções" seriam motivadas por paixões ou interesses particulares, antagônicos aos interesses dos cidadãos e dos interesses permanentes da comunidade.

A questão da desconfiança na política também tem sido estudada em várias partes do mundo desde meados do século passado. Análises comparadas revelaram, para os casos da Itália e da Alemanha, um grau de desconfiança "endêmico, generalizado e enraizado na sociedade" (Moisés, 2005, p. 47). Na Inglaterra, França e Suécia, os índices de confiança nas instituições caíram sistematicamente nos últimos trinta anos. A análise de pesquisas elaboradas nos últimos trinta anos demonstrou que os índices de confiança nas instituições e governos nestes países diminuíram de mais de $75 \%$ para aproximadamente $25 \%$. ${ }^{13}$ Diversos países que compuseram a terceira onda de democratização também apresentaram problemas associados à desconfiança (Huntington, 1991). A crise de 2008 contribuiu para reforçar esta tendência em países como Espanha, Portugal, Grécia , França e, como pode ser visto nos últimos resultados eleitorais para o parlamento em 2013, na Itália.

As nações latino-americanas também apresentaram estatísticas preocupantes a respeito da confiança em partidos políticos Com base em estudos sobre resultados eleitorais na América Latina, Baquero (2001, citado por Baquero, 2003, p. 89) assevera que "os eleitores parecem mais desconfiados e mais decepcionados com a política - a consequência parece ter sido a institucionalização

Para mais informações, ver Hamilton et. al. (1984).

A esse respeito, Moisés (2005) cita Klingemann (1999); Newton e Norris (2000); Dalton (1999). 
Artigo original

Hegemonia - Revista Eletrônica de Relações Internacionais do Centro Universitário Unieuro

ISSN: 1809-1261

UNIEURO, Brasília, número 11, 2013, pp. 69-98

de uma apatia generalizada em relação aos meios convencionais da política (partidos, eleições e procedimentos formais, de maneira geral)". Rubio (2005, p. 06) ressalta que, de acordo com o Latinobarômetro 2004, "pesquisa de opinião pública que abrange dezoito países da América Latina, mostra os partidos políticos como as instituições que menor confiança geram na população". Em outra pesquisa voltada para a América Latina, dois terços dos entrevistados demonstraram graus variados de desconfiança no Poder Legislativo, partidos políticos e tribunais de justiça, entre outros (Lagos, 1997). ${ }^{14}$ Na mesma linha, Dulci (2003) atenta para limitada credibilidade dos partidos brasileiros, que atingiram o patamar de $49 \%$ de desconfiança. Mais recentemente, Baquero \& Gonzáles (2012) assinalaram que a democracia encontra amplo suporte no Brasil. Contudo, o apoio político aos valores, instituições e gestores públicos tem declinado. Os cidadãos estão mais críticos em relação aos líderes políticos e as instituições governamentais. Ademais, identificam-se cada vez menos com partidos políticos e acreditam que o governo trabalha no sentido de beneficiar uma minoria. Noutras palavras, o apoio à democracia é contrastado pela insatisfação com relação à forma como as instituições democráticas funcionam no Brasil.

Por outro lado, na visão de Castillo (2003, p. 03), Inglehart "recusa que a erosão da confiança na política poderia estar associada a um fenômeno mais abrangente de alienação política". Para ele, não existe queda na participação política nas democracias ocidentais nos últimos trinta anos. Ao contrário, o que vem ocorrendo é uma "crise das tradicionais formas de participação convencional" que são dirigidas pelas elites econômicas e políticas. Concordando, Castillo (op. cit) assinala que os cidadãos ocidentais optaram por formas "não-convencionais" de participação, demonstrando a importância da crise de confiança nas instituições públicas.

Este autor apontou, com base em pesquisas desempenhadas pelo Latinobarômetro em dezessete países, que apenas $20 \%$ dos cidadãos confiam em partidos políticos. Menos de $30 \%$ declarou confiar nos governos, no Poder Legislativo e no judiciário, entre outros. 
Artigo original

Hegemonia - Revista Eletrônica de Relações Internacionais do Centro Universitário Unieuro

ISSN: $1809-1261$

UNIEURO, Brasília, número 11, 2013, pp. 69-98

Conclusão

A exposição sucinta do entendimento de vários autores e correntes sobre o conceito de democracia demonstra tanto a complexidade do tema quanto a sua importância para a construção de modelos de representação e tomada de decisões. A exposição dos conceitos de partido político e seus paradigmas também procurou demonstrar a complexidade da discussão teórica.

No que diz respeito à consolidação da democracia, é preciso chegar a um equilíbrio entre as diversas perspectivas, sobretudo a representativa e a participativa. Por um lado, as mudanças institucionais precisam ir além da preocupação excessivamente limitada com os procedimentos para a seleção de representantes e líderes. Elas precisam criar mecanismos que incentivem a participação política e que consigam estabelecer a confiança popular na democracia em patamares elevados. Por outro, é preciso manter um afastamento de conceitos e valores demasiadamente subjetivos. Ademais, faz-se necessário compreender que os objetivos esperados da consolidação democrática também dependem de outras condicionantes socioeconômicas e culturais. Em outras palavras, é salutar uma certa dose de ceticismo em relação aos resultados positivos que reformas institucionais podem alavancar, principalmente no caso brasileiro, país sujeito às mazelas da democracia delegativa, ou seja, marcado pela passividade e individualismo políticos, pelos legalismos e pela corrosão das instituições.

Paralelamente, o conjunto das diversas definições clássicas sobre os partidos políticos não dá ênfase consensual a nenhum tipo de compromisso de longo prazo com propostas, princípios ou ideologias. Elas estão em contradição com outras percepções das legendas como engajadas na promoção de uma agenda ideológica e na mobilização social. Nenhuma destas duas perspectivas se encaixa adequadamente na realidade atual, onde os partidos são "instituições 
Artigo original

Hegemonia - Revista Eletrônica de Relações Internacionais do Centro Universitário Unieuro

ISSN: $1809-1261$

UNIEURO, Brasília, número 11, 2013, pp. 69-98

semipúblicas" que representam muito mais modelos distintos de gestão do que ideologias. Além disso, são de modo geral altamente dependentes de financiamento estatal e intimamente ligadas à burocracia governamental. Portanto, precisam ser mais transparentes, mais inclusivas e menos oligarquizadas para que possam atenuar o quadro de desilusão com a política e auxiliar na consolidação da democracia.

Bibliografia

ABRÚCIO, F. L. Reforma política e Federalismo: desafios para a democratização brasileira. In: BENEVIDES, M.; KERCHE, F.; VANNUCHI, P. (Org.). Reforma política e cidadania. São Paulo: Fundação Perseu Abramo, 1a ed. 2003. p. 225-265.

BAQUERO, M. Construindo uma outra sociedade: o capital social na estruturação de uma cultura política participativa no Brasil. Curitiba: Revista de Sociologia Política, n. 21, p. 83-108, 2003. Disponível em: <http://www.scielo.br/scielo.php?script=sci_arttext\&pid $=$ S0104-44782003000200007\&lng =en\&nrm $=$ iso $>$.

BAQUERO, M. GONZÁLEZ, R. Obstáculos à construção de uma "nova" sociedade na América Latina. Qual é a utilidade do conceito de capital social nesse processo?. Revista Brasileira de Ciência Política, n. 3, p. 253-287, 2012.

BENEVIDES, M. Nós, O povo: reformas políticas para radicalizar a democracia. In: BENEVIDES, M.; KERCHE, F.; VANNUCHI, P. (Org.). Reforma política e cidadania. São Paulo: Fundação Perseu Abramo, $1 \mathrm{a}$ ed. 2003. pp. 83-119.

BONAVIDES, P. Ciência política. Rio de Janeiro: Fundação Getúlio Vargas, Serviço de Publicações. 2a ed. 1974. 
Artigo original

Hegemonia - Revista Eletrônica de Relações Internacionais do Centro Universitário Unieuro

ISSN: $1809-1261$

UNIEURO, Brasília, número 11, 2013, pp. 69-98

BONIFACIO, Robert. José Álvaro Moisés (org) - Democracia e confiança: por que os cidadãos desconfiam das instituições públicas?. Rev. Bras. Ciênc. Polít. [online]. 2012, n.7, pp. 399-406. ISSN 0103-3352.

CASTILLO, A. Political culture and representative democratic institutions in Spain. In: 6th ESA CONFERENCE, Political Sociology, Streams 9, 2003, Murcia. Proceedings published online. Disponível em: http://www.um.es/ESA/papers/St9_63.pdf.

COMPARATO, F. A garantia Constitucional contra o abuso de poder. In: BENEVIDES, M.; KERCHE, F.; VANNUCHI, P. (Org.). Reforma política e cidadania. São Paulo: Fundação Perseu Abramo, 1a ed. 2003. p. 44-56.

COSTA, P. R. N. Dossiê Democracia, políticos e partidos. Revista de Sociologia e Política, Curitiba, n. 15, p. 7-9, novembro 2000. Disponível em: http://www.scielo.br/pdf/rsocp/n15/a01n15.pdf.

DAHL, R. Poliarquia: participação e oposição. São Paulo: Edusp, 1997. 234 p.

- Sobre a Democracia. Brasília: Editora Universidade de Brasília, 2001.

DAHL, R. \& LINDBLOM, C. Política, economia e bem estar social. São Paulo: Lidador, 1971. 519 p.

DALTON, R. \& WELDON, S. Public images of political parties: a necessary evil? West European Politics, vol. 28, p. 931-51, 2005.

DULCI, O. S. A incômoda questão dos partidos no Brasil: notas para o debate da reforma política. In: BENEVIDES, M.; KERCHE, F.; VANNUCHI, P. (Org.). Reforma política e cidadania. São Paulo: Fundação Perseu Abramo, 1a ed. 2003. p.300-320.

DUVERger, M. Ciência Política Teoria e Método. Rio de Janeiro: Zahar Editores, 1a ed, 1962.

FIELD, C. G. Teoria Política. Rio de janeiro: Zahar Editores, 1a ed., 1959 .

HAMILTON, A.; MADISON, J.; JAY, J. O federalista. Brasília: Editora 
Artigo original

Hegemonia - Revista Eletrônica de Relações Internacionais do Centro Universitário Unieuro

ISSN: $1809-1261$

UNIEURO, Brasília, número 11, 2013, pp. 69-98

Universidade de Brasília, 1984.

HOFNUNG, M. (2008) Unaccounted Competition: The Finance of Intra-Party Elections. Party Politics, Sage Publications, vol 14. n.6 p. 726-744.

HUNTINGTON, S. The Third Wave. Democratization in the Late Twentieth Century. Oklahoma City: University of Oklahoma Press, 1991.

LAGOS, M. Latin America's smiling mask. Journal of Democracy, Washington: The Johns Hopkins University Press, n. 8. 1997.

LIJPHART, A. Democracies: forms, performance, and Constitutional engineering. European Journal of Political Research, 25, 1-17. January, 1994.

- Patterns of Democracy: government forms and performance in thirty-six countries. New Haven: Yale University Press, 1999.

- Modelos de Democracias. Rio de Janeiro: Civilização Brasileira, 2003.

MAINWARING, S. Sistemas partidários em novas democracias: o caso do Brasil. Porto Alegre/Rio de Janeiro: Mercado Aberto/FGV, 2001.

MANGAHAS, M. Social Climate: satisfaction with the way democracy works. Inquirer, Manila, 11 de novembro, 2007. Disponível em: http://opinion.inquirer.net/inquireropinion/ columns/ view_article.php?article_id=102832.

MANIN, B. As metamorfoses do governo representativo. Revista Brasileira de Ciências Sociais, n. 29, Ano 10, outubro de 1995. Disponível em: http://www.anpocs.org.br/portal/publicacoes/rbcs_00_29/rbcs29_0 1.htm

MICHELS, R. Sociologia dos partidos políticos. Brasília: Editora. UnB, 1982. Coleção Pensadores Políticos, n. 53.

MILIBAND, R. The state in capitalist society: an analysis of western system of power. New York: Ed. Basic Books, Inc., Publishers, 1985. MOISES, J. A desconfiança nas instituições democráticas. Opin. 
Artigo original

Hegemonia - Revista Eletrônica de Relações Internacionais do Centro Universitário Unieuro

ISSN: $1809-1261$

UNIEURO, Brasília, número 11, 2013, pp. 69-98

Publica, Campinas, v. 11, n. 1. p.33-63. 2005. DOI: 10.1590/S0104-62762005000100002. Disponível em: <http://www.scielo.br/scielo.php?script=sci_arttext\&pid=S0104$62762005000100002 \&$ Ing=en\&nrm=iso $>$.

NORRIS, P. Choosing electoral Systems: proportional, majoritarian and mixed systems. International Political Science Review, v. 18 (3), p. 297-312, julho de 1997. Edição especial: "Contrasting Political Institutions". Disponível em: www.pippanorris.com.

- Building political parties: reforming legal regulations and internal rules. Report for International IDEA Strengthening Parties, 2005.

Disponível

em:

http://www.idea.int/parties/upload/pippa\%20norris\%20ready\%20fo r\%20wev\%20_3_.pdf.

O`DONNELL, G. Democracia Delegativa?. Novos Estudos CEBRAP, São Paulo, n. 31, p. 25-40, 1991.

PAIVA, D.; SOUZA, M.R.; LOPES, G. de F. As percepções sobre democracia, cidadania e direitos. Opin. Publica, Campinas, v. 10, n. 2, p. 368-376. Oct. 2004 . Disponível em: <http://www.scielo.br/scielo.php?script=sci_arttext\&pid=S0104$62762004000200008 \&$ Ing $=$ en\&nrm=iso $>$.

PATEMAN, C. Participação e Teoria Democrátia. Rio de Janeiro: Paz e Terra, 1992. 187

PRZEWORSKI, A. Deliberation and ideológical domination. In: Elster, J. (Ed.). Deliberatve Democracy. Cambridge: Cambridge University Press, 1998. p. 140-160.

REIS, F. Atualidade mundial e desafios brasileiros. Estudos Avançados, São Paulo, v. 14, n. 39, 2000. DOI: 10.1590/S0103$40142000000200003 . \quad$ Disponível em: <http:// www.scielo.br/scielo.php?script=sci_arttext\&pid=S010340142000000200003\&lng = en\&nrm=iso $>$.

ROUSSEAU, J. Political Writings. Madison: University of Wisconsin Press, 1986.

RUBIO, D. F. Financiamento de partidos e campanhas: fundos 
Artigo original

Hegemonia - Revista Eletrônica de Relações Internacionais do Centro Universitário Unieuro

ISSN: $1809-1261$

UNIEURO, Brasília, número 11, 2013, pp. 69-98

públicos versus fundos privados. Novos Estudos - CEBRAP, São Paulo, n. 73, 2005. Disponível em: <http://www.scielo.br/scielo.php?script=sci_arttext\&pid=S0101$33002005000300001 \& \mathrm{lng}=\& \mathrm{nrm}=$ iso $>$.

SARTORI, G. Parties and party systems: a framework for analysis. Cambridge, Cambridge University Press, 1976.

1994.

A Teoria da Democracia Revisitada. São Paulo: Ed. Ática, . Engenharia Constitucional. Brasília: Ed. Universidade de Brasília, 1996.

SCHUMPETER, J. A. Capitalismo, Socialismo e Democracia. Rio de Janeiro: Ed. Fundo de Cultura, 1961.

SILVA, V. Partidos e reforma política. Revista Eletrônica sobre a Reforma do Estado (RERE), Salvador, Instituto Brasileiro de Direito Público, n. 10, p.01-11. Junho/agosto 2007. Disponível em: http://www.direitodoestado.com/revista/RERE-10-JUNHO-2007VIRGILIO\%20AFONSO.pdf.

TRINDADE, H. Reforma Política: os desafios da democracia social. In: BENEVIDES, M.; KERCHE, F.; VANNUCHI, P. (Org.). Reforma política e cidadania. São Paulo: Fundação Perseu Abramo, 1a ed. 2003. p. 57-82.

ZOVATTO, D. Financiamento dos partidos e campanhas eleitorais na América Latina: uma análise comparada. OPINIÃO PÚBLICA, Campinas, Vol. XI, no 2, p. 287-336, Outubro, 2005. 